\title{
ESPAÇO DA EDUCAÇÃO INFANTIL: A ABORDAGEM PEDAGÓGICA DE REGGIO EMILIA EM CONTEXTO PAULISTA
}

\author{
ESPACIO DE LA EDUCACIÓN INFANTIL: EL ENFOQUE PEDAGÓGICO DE REGGIO EMILIA EN \\ CONTEXTO DE SÃO PAULO
} SPACE FOR CHILDHOOD EDUCATION: THE REGGIO EMILIA PEDAGOGICAL APROACH
IMPLEMENTED AT SÃO PAULO STATE CONTEXT

\section{MACEDO, ADILSON COSTA}

Doutor em Arquitetura e Urbanismo, docente na Universidade São Judas Tadeu, ac.macedo@terra.com.br

\section{XAVIER, FABIO HENRIQUE DA COSTA}

Graduado em Arquitetura e Urbanismo, Universidade São Judas Tadeu, fh_xavier@hotmail.com

\section{IMBRONITO, MARIA ISABEL}

Doutora em Arquitetura e Urbanismo, docente na Universidade São Judas Tadeu, imbronito@gmail.com

\section{RESUMO}

Este artigo relata uma investigação na área da Arquitetura e sua relação com a Pedagogia visando analisar o espaço físico de uma escola de educação infantil. Definiu-se tomar como referência as escolas do sistema de ensino italiano de Reggio Emilia, cujo principal educador é Loris Malaguzzi, devido à estreita relação com a arquitetura e com a cidade que esta abordagem pedagógica estabelece. Com base no estudo de bibliografia especializada sobre as escolas de Reggio Emilia, no que se refere à origem da abordagem, à proposta pedagógica, à especificidade dos espaços das escolas e à relação com a comunidade, foram elencadas as necessidades programáticas, os elementos físicos e alguns aspectos de natureza qualitativa que dão base aos espaços das escolas. Na sequência, foi selecionada a Creche e Escola de Educação Infantil Almerinda Pereira Chaves (CEEIAPC), que pertence à Fundação Antônio Antonieta Cintra Gordinho (FAACG) e se localiza na cidade de Jundiaí, no estado de São Paulo, como estudo de caso da transposição da abordagem de Reggio Emilia a um contexto brasileiro. Foram feitas entrevistas e visita ao local para levantamento da linha adotada, dos espaços utilizados e das iniciativas tomadas pela escola para a adequação dos espaços préexistentes à proposta pedagógica da creche.

PALAVRAS-CHAVE: arquitetura escolar; espaço e ensino infantil; pedagogia da escuta.

\section{RESUMEN}

Este artículo reporta una investigación en el área de Arquitectura y su relación con la Pedagogía con el objetivo de analizar los espacios físicos de un jardín de infantes. Se tomó como referencia las escuelas del sistema educativo italiano de Reggio Emilia, cuyo educador principal es Loris Malaguzzi, debido a la estrecha relación con la arquitectura y con la ciudad que este enfoque pedagógico establece. Recorriendo al estudio de la bibliografía especializada sobre las escuelas de Reggio Emilia, sobre el origen del enfoque, la propuesta pedagógica, la especificidad de los espacios escolares y la relación con la comunidad, fueran levantadas las necesidades programáticas, las necesidades físicas y algunos aspectos de carácter cualitativo que dan la base de los espacios de las escuelas. La Guardería y la Escuela de Educación Infantil Almerinda Pereira Chaves (CEEIAPC), ubicada en la ciudad de Jundiaí, estado de São Paulo, y que pertenece a la Fundación Antonio Antonieta Cintra Gordinho (FAACG), fue seleccionada como un caso para estudio de la transposición del enfoque de Reggio Emilia a un contexto brasileño. Se realizaron entrevistas y una visita al lugar para examinar la línea adoptada, los espacios utilizados y las iniciativas tomadas por la escuela para adaptar los espacios preexistentes a la propuesta pedagógica del edificio escolar.

PALABRAS CLAVES: arquitectura escolar; espacio de la educación infantil; pedagogía de la escucha. 


\section{ABSTRACT}

This paper reports a research in the field of Architecture and its relation with Pedagogy aiming to analyze the physical space of kindergartens. It was decided to take the schools of the Italian Reggio Emilia education system as reference, whose main educator is Loris Malaguzzi, due to the close relationship that the educational approach establishes with the architecture and towards the city. Based on the study of specialized bibliography on the schools of Reggio Emilia, with regard to the origin of the approach, the pedagogical proposal, the specificity of the school spaces and the relationship with the community, the programmatic needs, the characterization of the physical spaces and aspects of a qualitative nature that give the basis of the spaces of the schools were perceived. The Nursery and Children Education School Almerinda Pereira Chaves (CEEIAPC), which belongs to the Antonio Antonieta Cintra Gordinho Foundation (FAACG), was selected among others as a study case of the transposition of the Reggio Emilia approach to a Brazilian context. It is located in the city of Jundiaí, in the state of São Paulo. Interviews were conducted and a site visit was made to survey the adopted line, the use of the spaces and the initiatives taken by the school to adapt the pre-existing building to the pedagogical proposal of the day care center.

KEYWORDS: school architecture; space and early childhood education; pedagogy of listening.

\section{INTRODUÇÃO}

Este trabalho, no campo da Arquitetura e Urbanismo, presume a importância de estabelecer uma aproximação entre arquitetura e educação infantil, para que desta aproximação resultem espaços adequados nas escolas, alinhados com a abordagem pedagógica adotada e que, ao mesmo tempo, contribuam para o desenvolvimento e a aprendizagem integral das crianças.

$\mathrm{Na}$ pesquisa estabeleceu-se que seriam estudados espaços escolares que valorizassem a combinação pedagogia-espaço como instrumento voltado para o aprendizado e a formação humana das crianças. A filosofia pedagógica escolhida foi a abordagem de Reggio Emilia, que tem como fundador e principal educador Loris Malaguzzi. Voltada para a educação infantil, a abordagem valoriza o espaço como um aspecto essencial no desenvolvimento das crianças, além de buscar constituir um vínculo da escola com a comunidade e com o meio urbano.

Para a compreensão da relação entre a abordagem pedagógica e o espaço da escola, a pesquisa foi desenvolvida nas seguintes partes: histórico da abordagem de Reggio Emilia; revisão dos conceitos da abordagem, com ênfase nos aspectos relacionados ao espaço e sua aplicação em escolas italianas, com consulta a sites e bibliografia especializada; escolha de uma escola brasileira inspirada na abordagem italiana - a Creche e Escola de Educação Infantil Almerinda Pereira Chaves, da Fundação Antônio Antonieta Cintra Gordinho, em Jundiaí, SP; visita à escola para levantamento físico e de uso; conversa com um dirigente da escola, realizada na data da visita técnica; considerações sobre a transposição da abordagem de Reggio Emilia à circunstância local paulista. As etapas estão descritas sequencialmente neste artigo.

\section{A ABORDAGEM DE REGGIO EMILIA}

A chamada abordagem pedagógica de Reggio Emilia para educação infantil, conhecida também como pedagogia da escuta, desenvolveu-se na Itália inspirada em algumas outras linhas, e aprimorou-se a partir das experiências locais. Essa filosofia incentiva o desenvolvimento autônomo das crianças e sua inclusão na sociedade como seres atuantes.

Uma das características essenciais dessa abordagem é a estreita relação estabelecida entre escola, crianças e comunidade. Esta relação remonta ao surgimento destas escolas pelas mãos da própria comunidade, com participação ativa dos pais nas decisões tomadas e sua frequência assídua à instituição, acompanhando de perto o desenvolvimento dos filhos.

A escola e as crianças desenvolvem atividades voltadas à comunidade, utilizam o espaço urbano no dia-adia ou assumem a própria cidade como objeto de interesse, o que reforça os laços entre escola e comunidade, e valoriza a infância perante a vida pública, contrariando abordagens em que a criança não possui visibilidade no contexto urbano e produtivo.

O conhecimento nas escolas de Reggio Emilia é construído por meio do desenvolvimento de projetos. As crianças e adolescentes aprendem a partir do envolvimento com assuntos que são, geralmente, transdisciplinares, e são incentivados a construir o conhecimento de forma empírica, complementado por estudos e discussões. A abordagem apoia-se na produção artística e no fazer como ferramentas do desenvolvimento humano, e entende que mente e corpo devem ser pensados conjuntamente. Incentivam- 
se atividades que contemplam simultaneamente pensar e fazer, e promove-se a autonomia ao enxergar a criança como um ser totalmente capaz.

Para tanto, as escolas do sistema Reggio Emilia apresentam espaços que possam acolher tais projetos e atividades práticas, compondo um programa de necessidades próprio. Além de disponibilizar, ao alcance das crianças, os meios para atividades ligadas ao "fazer", os espaços apresentam estímulos sensoriais como cores, texturas, luzes, sons ou cheiros, que incitam a curiosidade e permitem que a criança explore o mundo de forma tátil, considerada a forma primitiva de fazê-lo. Muitos dos pilares da abordagem de Reggio Emilia remontam ao período de sua formulação, ao fim da Segunda Guerra Mundial.

\section{História e formação}

A origem da experiência de Reggio Emilia data de 1945 e remete ao contexto de pós segunda guerra mundial. Malaguzzi conta, em entrevista a Lella Gandini publicada no livro As cem linguagens da criança: a abordagem de Reggio Emilia na educação da primeira infância, que se passavam apenas seis dias do fim da guerra quando ele tomou conhecimento da ideia que algumas famílias tiveram de construir e operar uma escola para crianças pequenas num vilarejo chamado Villa Cella, próximo à cidade de Reggio Emilia - ideia pela qual o educador se encantou.

Corri até lá em minha bicicleta e descobri que tudo aquilo era verdade. [...] As pessoas haviam se reunido e decidido que o dinheiro para começar a construção viria da venda de um tanque abandonado de guerra, uns poucos caminhões e alguns cavalos deixados para trás pelos alemães em retirada. (MALAGUZZI apud EDWARDS; GANDINI; FORMAN, 1999, p.72).

As famílias construíram a escola no terreno doado por um fazendeiro, com materiais reaproveitados das construções bombardeadas. Nota-se o embrião de um aspecto importante da abordagem de Reggio Emilia: a participação e envolvimento da comunidade, comprometida em agir pela educação das crianças. Com o auxílio do Comitê Nacional para a Libertação, outras sete escolas foram acrescentadas àquela primeira, todas conduzidas e operadas pelos pais.

Malaguzzi iniciou em Reggio Emilia um centro de saúde mental para auxiliar crianças com dificuldades na escola e, paralelamente, passou a dar aulas nestas escolas operadas pelos pais. Ali encontrou a motivação que buscava: professores com formações diversas, pensamento amplo e muita energia, e participação aberta dos pais, atuando junto com os professores e escutando as crianças.

Nosso objetivo é construir uma escola confortável, onde crianças, professores e famílias sintam-se em casa. Essa escola exige o pensamento e o planejamento cuidadosos com relação aos procedimentos, às motivações e aos interesses. Ela deve incorporar meios de intensificar os relacionamentos entre os três protagonistas centrais - crianças, pais e professores. (MALAGUZZI apud EDWARDS; GANDINI; FORMAN, 1999, p.72).

Em 1963, a municipalidade assumiu a gestão da primeira escola para crianças pequenas, a escola Robinson Crusoe. Tal evento trouxe a possibilidade de uma estruturação em maior escala destas escolas e, em contrapartida, a responsabilidade de constituir um modo de ensino consistente, que fosse aceito em uma região onde a educação católica estava socialmente e culturalmente enraizada.

Recebemos os primeiros grupos de professores especializados nas escolas administradas pelos pais. As responsabilidades estavam claras em nossas mentes; muitos olhos, nem todos amistosos, observavam-nos. Tínhamos que cometer o mínimo possível de erros. Precisávamos descobrir nossa própria identidade cultural rapidamente, tornarmo-nos conhecidos e conquistar confiança e respeito. (MALAGUZZI apud EDWARDS; GANDINI; FORMAN, 1999, p.62).

A necessidade de reconhecimento e aproximação com a comunidade resultou numa prática que caracterizou a abordagem: uma vez por semana, as atividades da escola ocorriam em parques, praças e espaços públicos citadinos. Dentro de um caminhão, os professores levavam os equipamentos necessários. As crianças se divertiam, e as pessoas que passavam surpreendiam-se e envolviam-se, aumentando a interação entre as crianças, a comunidade e os espaços da cidade.

Desde o início, a proposta educativa dessas escolas se baseou numa pedagogia de projetos: o aprendizado era atingido ao se desenvolverem atividades, na maioria dos casos em grupo, que abordam o conhecimento de forma transdisciplinar. Isso implica na necessidade de espaços capazes de acolher as atividades e os projetos. 
Além da apropriação de espaços urbanos, Malaguzzi e outros educadores refletiram sobre os espaços adequados para atender às necessidades das escolas e que permitissem a realização das atividades com base em projetos. Trataremos, então, de apresentar o programa básico das escolas de Reggio Emilia e, na sequência, os aspectos complementares que norteiam a concepção de tais espaços.

\title{
3 ESPAÇOS E ATIVIDADES
}

As escolas de Reggio Emilia, apesar de suas particularidades físicas, seguem um programa arquitetônico básico, resumido nos tópicos a seguir.

- Há um generoso hall de entrada que recebe as crianças, os pais e visitantes. Esse espaço, segundo Malaguzzi, além da função de recepção, tem como objetivo documentar e informar. Acredita-se que a exposição dos trabalhos produzidos pelas crianças tem grande importância no processo de aprendizagem, tanto por tornar essa produção de conhecimento dos pais, exaltando a capacidade das crianças, quanto para as próprias crianças, que se sentem seguras quanto à sua produção, podendo afetar o ambiente em que vivem e aprender com a produção uns dos outros.

- O hall leva as crianças ao refeitório e cozinha - que ocupa posição central nas escolas, e também apresenta ligação direta com um importante espaço de convívio: a piazza.

- A piazza é um pátio interior, espaço de convívio entre crianças, pais, professores e funcionários. O nome é derivado das piazzas italianas, e alude à convivência urbana, espaço citadino de trocas, diálogo e aprendizado da vida pública. A alusão a um espaço com tal vitalidade evidencia o vínculo da escola com a cidade.

\begin{abstract}
O espaço comum tradicional presente em muitas de nossas escolas, por exemplo, foi transformado em uma praça que catalisaria muitos tipos de encontros interessantes. A entrada tornou-se um "cartão de visita" metafórico, introduzindo e fornecendo informações sobre a escola e seus habitantes; as áreas de serviço (cozinha e banheiros) adquiriram a importância que mereciam e foram metaforicamente transferidas da periferia para uma área central da planta. (VECCHI, 2003, p.128-129, tradução nossa).
\end{abstract}

- Conectadas à piazza, mas conservando a concentração necessária aos espaços de trabalho, encontram-se as salas de aula. Cada sala, espaço de identificação para os grupos de crianças, é dividida em dois espaços, um gregário e outro reservado, o que permite que a criança possa tanto estar no grupo, em contato direto com o professor, quanto dedicar-se a atividades introspectivas no espaço lindeiro. Isso cria na criança uma noção de responsabilidade e permite diferentes níveis de envolvimento e concentração. Esse segundo espaço das salas também pode ser utilizado para o desenvolvimento de atividades em grupos pequenos, ou ainda ser incorporado como uma extensão do espaço comum.

- O programa básico inclui também espaços para experimentação e produção artística. São esses: o ateliê, o laboratório e o estúdio, onde se trabalha especialmente a linguagem visual, relacionada ou não à linguagem verbal. A produção artística é bastante evidenciada nas escolas de Reggio Emilia. Surge o papel do atelierista, pessoa responsável por (i)gerir as atividades do ateliê e as atividades extraclasse; (ii) documentar estas atividades, mantendo a memória e produzindo material expositivo para dar visibilidade às mesmas.

- Posteriormente, além do ateliê comum, foram incluídos mini-ateliês. A cada sala de aula, que já possuía dois espaços (um coletivo e outro mais introspectivo) foi acrescentado um mini-ateliê para o desenvolvimento de trabalhos mais extensos junto àquele grupo.

Um dos novos espaços, que chamamos de "mini-atelier", porque tem o mesmo tipo de materiais e oferece oportunidades semelhantes ao do atelier central, acabou por ser uma mudança importante que foi gradualmente feita em todas as escolas municipais. (VECCHI, 2003, p.129, tradução nossa).

- Cada escola possui ainda uma sala de música e um arquivo, onde são guardados diversos objetos úteis e não-comerciais.

É importante ressaltar que muitas dessas 'divisões' entre os espaços são feitas com o uso do vidro, mantendo a comunicação e transparência entre os ambientes. 
Edwards, Gandini e Forman (1999) dedicam um capítulo de seu livro para tratar do espaço a partir de questões qualitativas, que vão além do programa arquitetônico, abordando aspectos sociais ou sensoriais. Tal capítulo é dividido em subcapítulos elencados a seguir, para que se possa caracterizar a atmosfera em que as crianças são inseridas.

\title{
O espaço como um elemento essencial da abordagem educacional
}

Edwards, Gandini e Forman (1999) ressaltam a importância do espaço na metodologia de Reggio Emilia, em aspectos além daqueles indispensáveis de organização, segurança e utilidade, buscando um entendimento profundo do que o espaço representa, de como ele é interpretado e de como se torna catalizador das relações humanas. Nas escolas de Reggio Emilia, a hierarquia espacial rígida é abolida: todos os espaços são essenciais e se interligam - física ou visualmente -, permitindo a interação e comunicação desejadas. Por fim, apesar das instituições seguirem um mesmo programa de necessidades, cada escola é única, pois é resultado de sua história e cultura particulares de modo que, espacialmente, ela reflete seus ocupantes. Uma vez que cada escola é oriunda do lugar, daquela comunidade e de seus ocupantes, ela deve tanto refletir a comunidade como facilitar sua acolhida.

\section{O espaço arquitetônico planejado}

Ao se pensar o arcabouço do espaço da escola, é importante a participação da comunidade, uma vez que ela irá conviver cotidianamente neste ambiente. Além disso, sob este arcabouço, ocorre a transformação contínua dos espaços conforme os usos. Segundo Malaguzzi, o sistema de ensino de Reggio Emilia precisa renovar-se periodicamente e, consequentemente, altera-se também o espaço escolar. Portanto, seus espaços precisam ser flexíveis para suportar as camadas de elementos que se acumulam, e que são trocadas de tempos em tempos. O espaço é entendido como um organismo vivo.

\begin{abstract}
Pensamos em uma escola para crianças pequenas como um organismo vivo integral, como um local de vidas e relacionamentos compartilhados entre muitos adultos e crianças. Pensamos na escola como uma espécie de construção em contínuo ajuste. Certamente precisamos ajustar nosso sistema de tempos em tempos, enquanto o organismo percorre seu curso de vida, exatamente como aqueles navios-pirata eram obrigados a consertar suas velas e, ao mesmo tempo, manter seu curso no mar. (MALAGUZZI, s/d, apud EDWARDS; GANDINI; FORMAN, 1999, p.72).

Um espaço responsivo e transformável, que possibilita diferentes formas de habitar e usar durante o decorrer do dia e com o passar do tempo. O espaço também deve ser personalizável, aconchegante, aberto a receber impressões. (...) O espaço, então, como um organismo vivo, deve ser capaz de mudar e evoluir de acordo com o projeto cultural de quem nele habita, mantendo as características genéticas do projeto de design. (CEPPI; ZINI, 2003, p.18, tradução nossa).
\end{abstract}

\section{O espaço maior em torno da escola, da cidade e além}

Avançando na relação cidade-escola, os idealizadores da pedagogia da escuta compreendem a importância de pensar as escolas junto aos planos urbanos. Sabendo que a educação é baseada na relação com a comunidade, as escolas devem ocupar um papel de destaque na cidade e tornarem-se ponto focal da interação entre as pessoas a elas vinculadas. Além de chamar a atenção da comunidade para a escola, para Malaguzzi a interação e apropriação dos espaços da cidade pelas crianças também é parte do processo de aprendizagem infantil, construindo uma formação cidadã e reforçando a participação do sujeito enquanto integrante da sociedade. Desta maneira, algumas atividades das crianças têm lugar no próprio espaço urbano, produzindo referências e relações, e explorando os espaços da cidade e sua dinâmica como objeto de estudo. Ao mesmo tempo, paralelamente, o convívio no ambiente da escola ensaia a vida comum, referenciando-se a elementos como feiras, praças, festas, etc., numa espécie de microambiente urbano.

Uma escola não deve ser uma espécie de contra-mundo, mas a essência e destilação da sociedade. A realidade contemporânea pode e deve permear a escola, filtrada por um projeto cultural de interpretação que serve de membrana e interface. Há muitos componentes de uma cidade e suas atividades diárias na escola para crianças pequenas, assim como o trabalho diário na escola cria um microcosmo da sociedade. (CEPPI; ZINI, 2003, p.15, tradução nossa). 
Os professores também valorizam o que é especial sobre os espaços que cercam suas escolas, considerando-os como extensões do espaço da sala de aula. Parte do seu currículo envolve levar as crianças para que explorem as vizinhanças e os marcos da cidade. Um exemplo da extensão da escola é um projeto levado avante por muitos meses pela escola Villetta, durante o qual as crianças saíram para explorar o modo como a cidade transforma-se durante os períodos de chuvas. (EDWARDS; GANDINI; FORMAN, 1999, p.148).

\title{
O espaço hospitaleiro como um reflexo das camadas de cultura
}

Nesta parte do texto, Edwards, Gandini e Forman (1999) ressaltam o cuidado ao gerir e dispor do espaço da escola. A organização cuidadosa dos espaços e o movimento criado pelas pessoas que nele circulam imprimem nas escolas o que se denomina de caráter hospitaleiro. Uma atmosfera receptiva e acolhedora é percebida no arranjo dos detalhes e dos objetos, o que é capaz de transformar o espaço saturado e caótico em um espaço balanceado e confortável.

Os diversos elementos disponíveis às crianças ficam agrupados de modo a propiciar uma interação a partir de relações e afinidades. Esta dinâmica própria complementa a configuração física do espaço, com grandes janelas, jardins bem cuidados e móveis funcionais.

\begin{abstract}
Na minha primeira visita a uma das pré-escolas de Reggio Emilia [...] eu esperava que o espaço clássico saturado de cores e objetos, um pouco caótico, fosse o tipo de espaço que a imaginação dos adultos normalmente considera estimulante para as crianças. Para minha surpresa, porém, encontrei-me em um ambiente equilibrado, rico em percepções de cores e materiais, mas sem essa ênfase exagerada com a qual muitas vezes conotamos espaços para a criatividade e o desdobramento livre da imaginação. (RETRILLO, 2003, p.138).
\end{abstract}

\section{Espaço social, espaço individual e espaço aparentemente marginal}

Neste subcapítulo, os autores destacam a importância dos espaços das escolas visando a interação entre diferentes agentes: crianças, professores, funcionários e pais. Busca-se a criação de espaços específicos para que pais se reúnam e possam discutir problemas, participar de atividades ou sociabilizar, facilitando o envolvimento dos pais nas decisões e nos processos de aprendizagem das crianças. Nota-se que as escolas de Reggio Emilia são projetadas a partir do princípio da horizontalidade do prédio que reflete uma horizontalidade das relações, salvos casos em que a topografia do terreno não permita.

\section{Espaço apropriado para diferentes idades e níveis de desenvolvimento}

O espaço das escolas infantis de Reggio Emilia é preparado para atender às crianças em nas fases diferentes de desenvolvimento (EDWARDS, GANDINI, FORMAN, 1999). Assim, uma atmosfera de "intimidade e envolvimento" é observada nas creches - salas forradas com carpetes e travesseiros, para que as crianças fiquem livres com segurança, e espaços de exploração com tintas, farinha e outros materiais sensoriais. Por sua vez, na pré-escola, crianças um pouco maiores encontram espaços providos com materiais não estruturados como Legos, materiais reciclados e animais de brinquedo, com espaço dedicado à brincadeira no chão, cobertos de tapetes e almofadas. Já salas para crianças maiores são mais propícias à experimentação dirigida, disponibilizando materiais para a elaboração de seus projetos.

Outro fundamento importante para pensar a escola de Reggio Emilia é que ela seja concebida como um espaço com diferentes microambientes, o que é chamado de "um lugar de lugares". Grupos poderão conviver e dividir os espaços comuns, desenvolvendo uma complexa sensação de território.

Um espaço pré-escolar precisa fornecer lugares para cada indivíduo que o ocupa: o meu e o teu. Mas também deve ser um espaço comunitário: o nosso. "Nosso" espaço pode assumir muitas formas: lugares para conversar em duplas ou para reunir toda a escola, locais para pintar ou observar pássaros. Um bom espaço tem espaço para diversos lugares. (BRUNER, 2003, p.137).

\section{Espaço organizado, espaço ativo e espaço particular}

Para as atividades dos projetos desenvolvidos cotidianamente nas escolas da Reggio Emilia, as salas de aula e os ateliês são organizados com os elementos e as ferramentas necessárias para a realização das atividades. Há muito cuidado em dispor tudo de modo atrativo, ofertar os objetos, de modo organizado, ao 
alcance da mão: são conjuntos de coisas disponíveis para serem articulados, montados, ressignificados. Os espaços contêm prateleiras e caixas abertas e separadas por categorias de materiais, reciclados e nãoreciclados. A imagem evocada por Malaguzzi para referir-se à disposição dos materiais a serem selecionados e apropriados ou transformados pelas crianças é a de bancas de mercado (feira), onde os fregueses buscam as mercadorias que lhes interessam, fazem sua seleção e engajam-se em interações intensas. O espaço é, portanto, pensado em diversas escalas: desde a relação com a cidade, ao arranjo do programa arquitetônico e a organização geral da escola, até o nível de detalhamento do mobiliário e do arranjo de objetos sobre uma mesa de trabalho - tudo para o estímulo, facilitação e autonomia da experiência das crianças.

\title{
O espaço que documenta
}

A documentação das atividades e projetos é mais um dos pontos essenciais da abordagem de Reggio Emilia. Liderado pelo(a) atelierista, esse processo ocorre ao longo do desenvolvimento dos projetos e é feito por meio de diversas mídias: fotografias do processo, textos, ilustrações. Além da documentação de vários projetos ter como destino a publicação em catálogos - como 'Mosaic of marks, words, materials' (REGGIO CHILDREN, 2014), e 'Everything has a shadow, except ants' (REGGIO CHILDREN, 1999) -, esse processo é levado ao cotidiano de todos os que vivem a escola e em seu entorno. Os registros dos processos são exibidos nos espaços da escola, colados em paredes, painéis, expostos no hall de entrada, e isso contribui na criação da atmosfera da escola. Ao se verem representadas, as crianças ficam mais confiantes para propor e projetar, e são instigadas a continuar os processos. As paredes da escola são suporte das histórias e dos processos vividos pelas crianças.

\begin{abstract}
Um dos aspectos do espaço que surpreende os visitantes é de fato a quantidade de trabalhos das próprias crianças exibidos por todos os cantos nas escolas. Na verdade, essa é uma das principais contribuições das crianças para moldarem o espaço de sua escola. Fazem isso pela mediação dos professores e especialmente do atelierista, que seleciona e prepara as exibições com muito cuidado. (EDWARDS; GANDINI; FORMAN, 1999, p.155).
\end{abstract}

Em toda a escola, as paredes são usadas como espaços para exibições temporárias e permanentes do que as crianças e os professores criaram: nossas paredes falam e documentam. (MALAGUZZI apud EDWARDS; GANDINI; FORMAN, 1999, p.73).

\section{Outros aspectos espaciais}

Os educadores de Reggio Emilia vêm o espaço como um container que favorece a interação social, mas que também apresenta um conteúdo educacional: além do espaço escolar ser um invólucro dentro do qual as relações podem se desenvolver, ele deve também ser um espaço que ensina, contendo mensagens e estímulos para a experiência interativa da aprendizagem. Para tanto, ao projetar uma escola que atenda às demandas da pedagogia empregada em Reggio Emilia, é preciso dar atenção a fatores que muito vão além do programa arquitetônico em si e são do âmbito da percepção sensível, como luz, som e cheiros.

O emprego da luz não visa a homogeneidade e a eficiência luminosa, mas a criação de diferentes atmosferas. A iluminação artificial é utilizada de modo que crianças possam manipulá-la, tornando a luz um componente material e tátil. Também incentivam-se espaços que permitam ver o exterior, para que a luz natural informe às crianças sobre a passagem do tempo.

Desta forma, a luz natural torna-se um material vivo que pode ser manipulado e usado pelas crianças para produzir suas próprias configurações estéticas. A luz artificial em uma escola não deve ser uniforme ou monótona, embora esse seja frequentemente o caso das aplicações tradicionais de iluminação, em que é dada prioridade ao estabelecimento de visibilidade constante e igual em cada ponto do espaço. (CEPPI; ZINI, 2003, p. 46, tradução nossa).

O tratamento de cores e texturas das superfícies é valorizado na composição dos espaços das escolas de Reggio Emilia, através de pinturas, papéis, estampas, objetos dispostos pelo espaço e mobiliário. Afirma-se que cores e texturas auxiliam no desenvolvimento das crianças: ao explorarem com autonomia os espaços repletos desses estímulos, elas adquirem uma ampla percepção sobre materiais, suas propriedades e sobre o mundo ao redor. 


\section{Objetos no espaço - a ocupação ao longo do tempo}

Por fim, destaca-se que o esforço em planejar os espaços só ganha força no processo de ocupação e apropriação pelos usuários. O edifício vazio possui, por si só, diversos estímulos, mas a potência e o caráter do espaço são alcançados após algum tempo de utilização. É através da ação das pessoas no dia-a-dia que os espaços ganham vida. As paredes vazias passam a ser preenchidas; os espaços comuns são tomados por objetos coloridos, plantas, brinquedos, varais de luzes, quadros e materiais reciclados. A presença cotidiana dos grupos estabelece uma dinâmica nos espaços. Todos na escola, especialmente as crianças, com toda a liberdade de pensar, explorar e agir, tornam-se agentes do espaço, e adquirem a noção de que esse espaço também lhes pertence e é moldado por elas.

\section{ESTUDO DE CASO: CRECHE E ESCOLA DE EDUCAÇÃO INFANTIL ALMERINDA PEREIRA CHAVES}

Dentre as escolas paulistas identificadas como vinculadas à abordagem pedagógica de Reggio Emilia, selecionamos a Creche e Escola de Educação Infantil Almerinda Pereira Chaves (CEEIAPC) para concretizar esta etapa da pesquisa. A escola, situada em Jundiaí, SP, é uma das escolas geridas pela Fundação Antônio Antonieta Cintra Gordinho (FAACG), organização filantrópica que administra unidades de ensino que atendem crianças a adolescentes desde a creche até o nível médio e técnico.

Estabelecido o contato com a direção da FAACG e com a coordenadora pedagógica da CEEIAPC, foi feita a visita técnica e esclarecimento de dúvidas sobre a abordagem utilizada e sobre as adaptações necessárias no espaço para a transposição das ideias de Reggio Emilia para o contexto da cidade paulista. Os resultados obtidos a partir das conversas, visita à escola e levantamentos fotográficos serão apresentados a seguir.

\section{Adaptações à abordagem pedagógica}

No levantamento in loco, foi constatado que o compromisso da CEEIAPC com a abordagem de Reggio Emilia é intenso, manifestado em pesquisas acadêmicas, literatura especializada disponível na escola e ações pedagógicas cotidianas. A coordenadora pedagógica da unidade manifestou a consciência de que a escola precisa estar em processo de aperfeiçoamento contínuo, e relatou a realização semanal de formação no contexto da escola, além de uma formação anual com uma dupla de profissionais provenientes da Itália. Por fim, há contato contínuo com o Centro Internacional Loris Malaguzzi, que oferece material e cursos de instrução sobre a abordagem. Os profissionais da escola, além de se capacitarem, são responsáveis por levar o entendimento do processo aplicado na creche para os pais e para a comunidade, impactando na dinâmica pais-escola e no aproveitamento como um todo.

Um desafio encontrado é fazer com que a linha pedagógica pretendida pela escola dialogue com a Base Nacional Comum Curricular. Há a necessidade de adaptação da abordagem pedagógica, para que as atividades e os projetos na linha de Reggio Emilia sejam feitos ao mesmo tempo em que se cumpre o programa de ensino estabelecido pelo MEC. Uma ação que tem contribuído para a aproximação entre as abordagens é a participação da diretora de formação da FAACG como membro do Conselho Estadual de Educação de São Paulo, introduzindo a discussão sobre a abordagem na escala do Estado. Vale ressaltar que a diretora concluiu Doutorado na Faculdade de Educação da Universidade de São Paulo, em 2011, com a tese $A$ construção da parceria família-creche: expectativas, pensamentos e fazeres no cuidado e educação da criança (SILVA, 2011), e que trabalhou na Itália em uma das escolas de Reggio Emilia, onde conheceu mais profundamente a abordagem.

O contexto social encontrado em Jundiaí é diferente daquele encontrado nas escolas italianas. Em Jundiaí, a Fundação Antonio Antonieta Cintra Gordinho (FAACG) cumpre um importante papel social de cuidado com as crianças, uma vez que se dedica a aceitar apenas uma população em condição de extrema fragilidade econômica. O público atendido na Escola Almerinda Pereira Chaves é composto por 85 crianças com idade entre 4 meses e 5 anos e renda familiar de até 1,5 salários mínimos. Os pais, estimulados a participar da vida escolar e da educação dos filhos, dependem da escola para a acolhida e cuidado das crianças durante a jornada de trabalho. 


\section{Adaptações ao meio e ao espaço}

A escola em Jundiaí está implantada em uma localidade não central, e a presença da escola na cidade torna-se diluída, com pouco uso dos espaços públicos no entorno da escola pelas crianças. Essa característica é compensada pelo intenso uso do terreno da escola. Nota-se ainda, pela conformação do edifício e pela grande dimensão do terreno da creche, uma referência à cultura local com acento rural, o que é interessante para estabelecer o vínculo entre a escola e a comunidade.

Com relação aos espaços da Escola Almerinda Pereira Chaves, visando entender a transposição da filosofia italiana à realidade de Jundiaí, a primeira consideração a ser feita é que a escola ocupa um prédio pré-existente construído em 1981, num momento em que as creches eram responsabilidade da Assistência Social, implantado em um lote cedido pela Prefeitura. Assim, diferentemente dos edifícios projetados juntos à implementação da abordagem pedagógica, em Jundiaí ocorreu um processo de adaptação dos espaços do edifício. Na medida do possível, este cumpre seu papel como agente na educação das crianças: o edifício é sólido, espaçoso e bem proporcionado, apropriado ao uso escolar convencional. Não condiz, contudo, com a grande comunicação, fluidez e transparência entre os espaços proposto pela abordagem de Reggio Emilia. Nesse sentido verifica-se que:

- A pequeníssima varanda à frente do edifício faz a vez de lugar de chegada e acolhimento que, neste caso, compensa as pequenas dimensões com o espaço exterior circundante, uma vez que, em nosso país, o clima é mais favorável à permanência externa.

- O corredor central, cuja largura é útil, foi gradualmente transformado, de espaço de passagem, para espaço que informa.

\section{Espaços da creche e suas atividades}

O edifício da CEEIAPC é um galpão amplo e bem construído, com área de $550 \mathrm{~m}^{2}$, num grande terreno que propicia área externa abundante para que as crianças brinquem, plantem e desenvolvem projetos. Os ambientes internos contêm salas de aula, um ateliê e um amplo refeitório (Figura 1). Além desses espaços, há sala de professores, coordenação, enfermaria, uma saleta de espera/informações, e uma sala administrativa com espaço reservado ao serviço social, além dos vestiários e serviço dos funcionários (em prédio anexo).

Novamente, são encontradas algumas divergências com relação às escolas de Reggio Emilia, em consequência do contexto encontrado. Nesse campo, três elementos se destacam:

- Na Itália, as escolas são conhecidas pela ausência de corredores, uma vez que os espaços são organizados em torno da piazza, espaço de convívio central em proximidade ao ateliê. A piazza não está presente na CEEIAPC, cujos espaços são tradicionalmente ordenados em linha ao longo do corredor longitudinal.

- Outra diferença é que o ateliê, na escola de Jundiaí, fica externo ao corpo principal da escola, em um galpão anexo.

- A terceira grande diferença é a ausência dos mini-ateliês que, em Reggio Emilia, são incorporados a cada sala de aula.

Apesar dessas diferenças, há vários elementos em comum entre o modelo italiano e a escola brasileira, em sua maioria relacionados à ocupação móvel e à gestão do espaço. Existe a consciência de que a escola enfrenta condições específicas e está em constante aprimoramento, processo que fica claro em um painel preso a uma das paredes do corredor central, que apresenta fotos dos espaços da escola antes e depois da implementação da abordagem de Reggio Emilia: as mudanças foram muitas, e os espaços, apesar do arcabouço fixo de um prédio em boas condições, foram adaptados internamente sob diversos aspectos. 
Figura 1 - Planta esquemática da CEEIAPC.

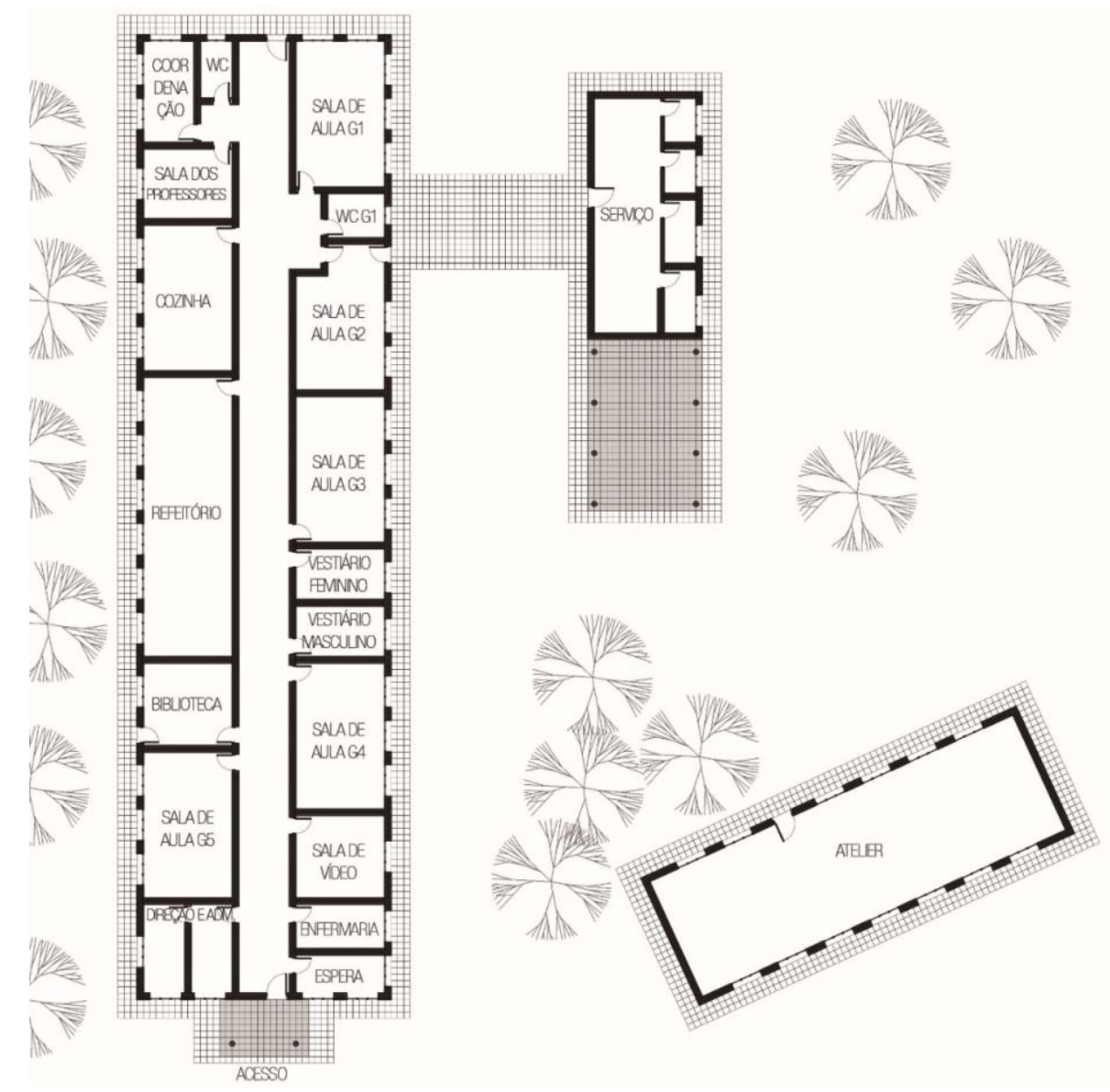

Fonte: Desenhado pelos autores a partir de levantamento feito no local (2018).

\section{Características dos espaços}

Para além da determinação programática dos espaços, há uma série de elementos que caracterizam os espaços das escolas de Reggio Emilia que estão presentes na CEEIAPC. Encontramos em Jundiaí a concepção das paredes que falam: a documentação e exposição dos projetos das crianças faz com que elas se reconheçam no ambiente escolar e a comunidade conheça o cotidiano da escola. Ao visitar a CEEIAPC, encontramos o registro das atividades das crianças e dos processos, principalmente no corredor do edifício, que ganhou assim um caráter e uso a mais, de estabelecer a interface com os pais. É possível identificar os trabalhos desenvolvidos na escola simplesmente ao passear por ela (Figura 2). Também é importante notar a placa de identificação dos espaços da escola, feita pelas crianças. O registro cotidiano das atividades das crianças também fica público em um livro na entrada de cada sala, podendo ser consultado pelos pais, profissionais e visitantes.

Outro aspecto das escolas de Reggio Emilia presente em Jundiaí é o conceito do espaço como um "lugar de lugares". Cada sala é ocupada com diferentes microambientes, o que permite que as crianças estejam todas juntas, em grupos menores ou em atividades solitárias, reforçando a autonomia concedida a elas. $\mathrm{Na}$ escola de Jundiaí, a organização interna das salas de aula caracteriza-se pela concentração de mobiliários e objetos afins, agrupados entre si mas com a manutenção de hiatos ou espaços vazios entre cada microambiente, possibilitando a noção de espaços diferenciados aptos a propiciar vários tipos de vivências (Figura 3). Os objetos são cuidadosamente oferecidos, podendo-se notar um princípio organizativo nos arranjos. Os objetos ficam disponíveis à mão das crianças em uma provocante disposição, sendo que sua combinação é propositalmente arranjada, como a lupa para observar a planta que cresce ou a trena e a lanterna para fazer experiências com o globo terrestre (Figura 4). 
Macedo, A. C.; Xavier, F. H. C.; Imbronito, M. I.

Figura 2. Corredor com diversas informações sobre as atividades em andamento na escola. A sinalização dos ambientes da escola é feita com desenhos das crianças.
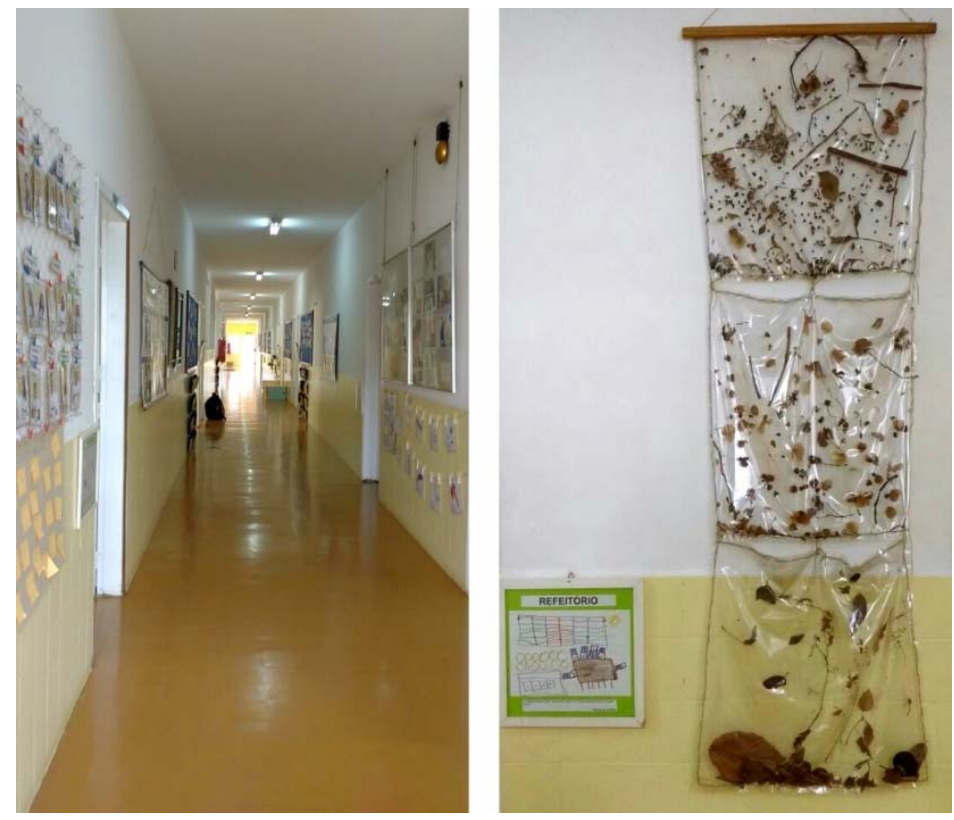

Fonte: Fotos dos autores (2018).

Figura 3. Diferentes microambientes que compõem sala da CEEIAPC para crianças maiores. Objetos cuidadosamente dispostos: o globo terrestre é combinado com lanternas e instrumentos de medir e observar.

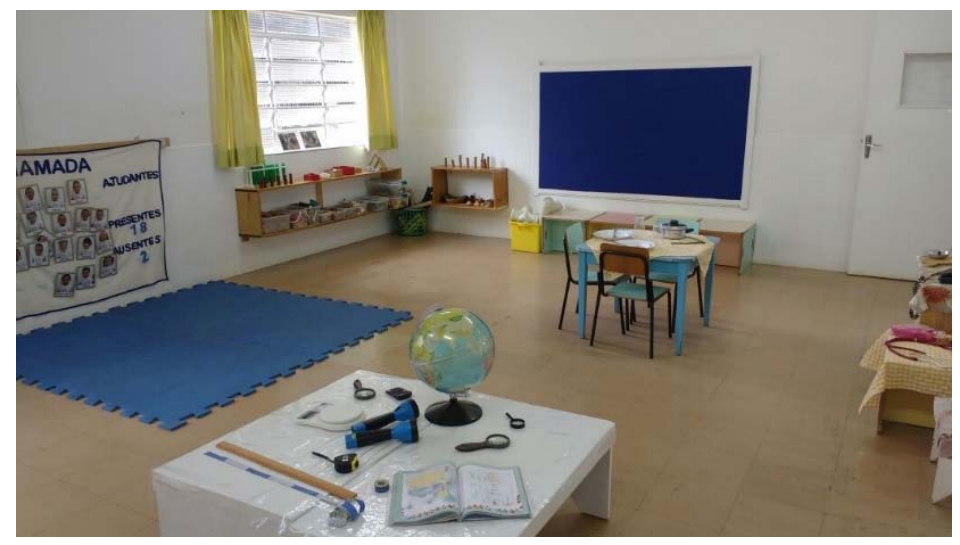

Fonte: Foto dos autores (2018).

Figura 4. Detalhe da prateleira com objetos dispostos como banca de feira.

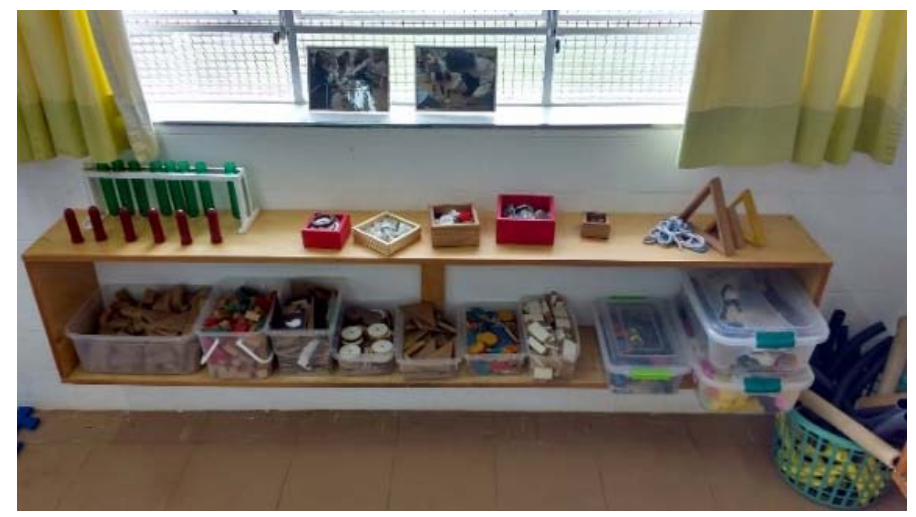

Fonte: Foto dos autores (2018). 
A área externa da escola é bastante explorada pelas crianças no decorrer dos projetos (Figuras 5 e 6), o que é uma diferença com relação às escolas italianas, que apresentam clima adverso em certas épocas do ano. Em Jundiaí, o destaque fica por conta da horta da escola. Já atividades desenvolvidas no espaço público citadino, prática incentivada pelas escolas italianas, está sendo gradualmente implementada na CEEIAPC, mas ainda permanece insipiente.

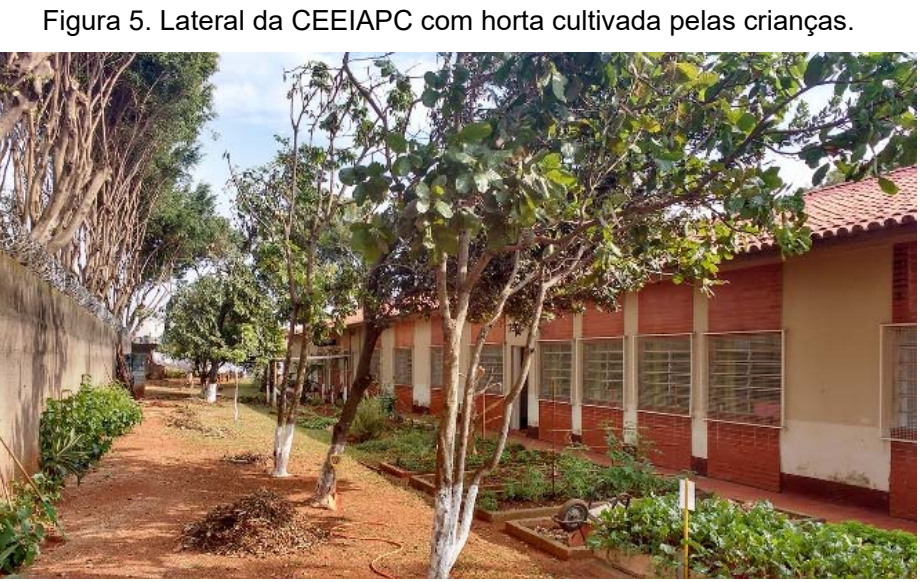

Fonte: Foto dos autores (2018).

Figura 6. Área externa também se apresenta como um lugar de lugares, em um conjunto de diversos microambientes.

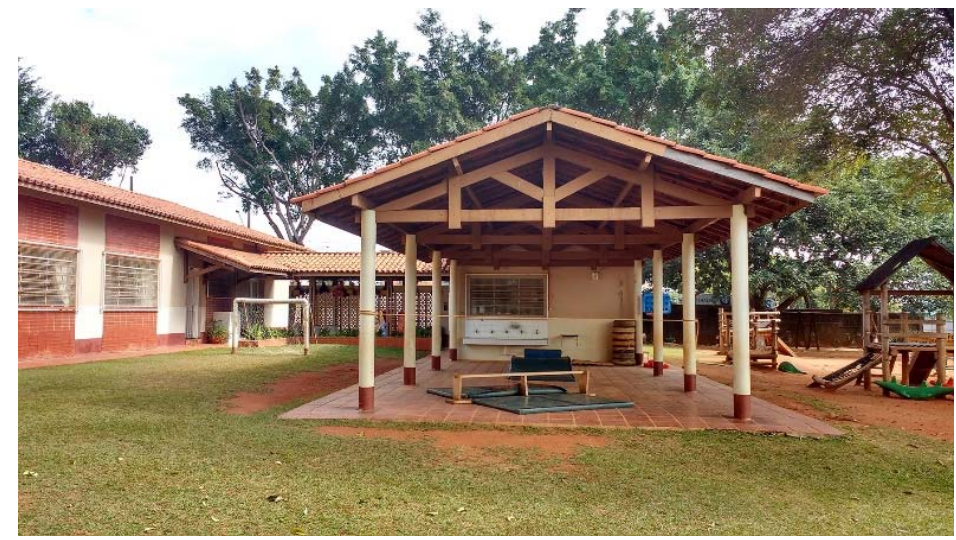

Fonte: Foto dos autores (2018).

\section{Outros elementos componentes do espaço: luz, cor, objetos.}

A luz é um elemento importante na construção dos espaços das escolas de Reggio Emilia. As escolas italianas utilizam amplamente a iluminação natural e artificial. A luz artificial, além de servir para o fim de iluminar, é utilizada como elemento manipulável pelas crianças, para experimentação e possibilidades de percepção e expressão. A luz natural ilumina os espaços, mas também mostra a passagem do tempo e as diferentes épocas do ano. Além disso, janelas entre ambientes internos auxiliam na disseminação da luz e permitem a comunicação entre diferentes espaços. Na escola de Jundiaí, é raro o uso de iluminação artificial como elemento manipulável: apenas um cordão de luz na biblioteca remete a um uso lúdico da iluminação. Identificamos na escola a ideia da comunicação entre os diferentes ambientes, possibilitada pelo uso de vidro entre o corredor principal, as salas de aula e o refeitório, mas a uma altura restrita ao nível do olhar dos adultos. Já a iluminação natural é abundante, uma vez que os ambientes retangulares tem a maior face contendo janelas (Figuras 7 e 8).

A escola de Jundiaí, no geral, apresenta cores neutras. A presença das cores fortes fica a cargo do mobiliário das salas de aula e do atelier, além dos objetos encontrados nesses ambientes, como lápis de cor, brinquedos e objetos não comerciais que são utilizados de forma lúdica. Dispostos como bancas de 
feira, assim como apregoava Malaguzzi, estes objetos ficam disponíveis para a escolha das crianças e as consequentes interações entre elas (Figura 10).

Outro ponto a destacar na CEEIAPC é o espaço do ateliê (Figura 9), um espaço de transformação de materiais, muitos deles não estruturados, coletados ou reaproveitados. Além da oferta de materiais, o ateliê mostra os trabalhos em andamento na escola.

Figura 7. Iluminação natural das salas do CEEIAPC.

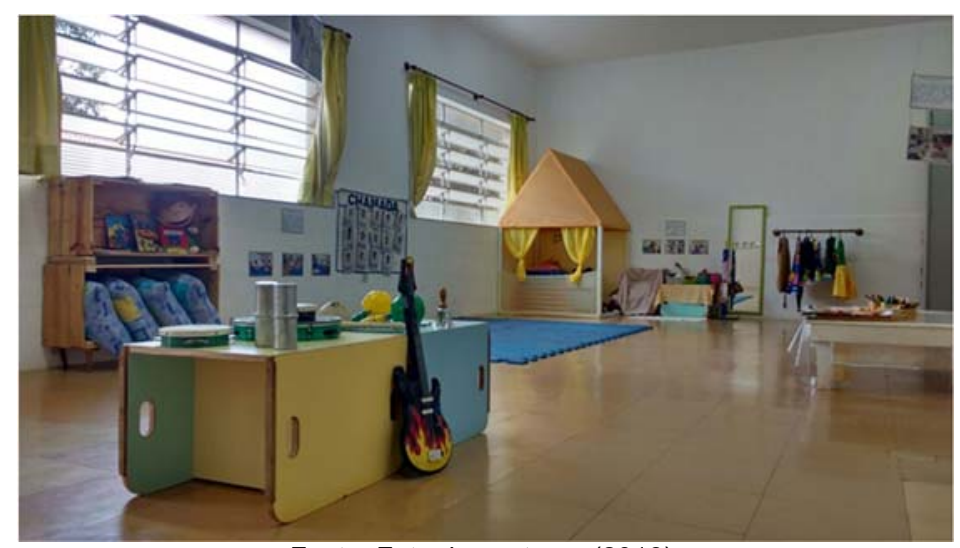

Fonte: Foto dos autores (2018).

Figura 8. Cordão de luz artificial na biblioteca.

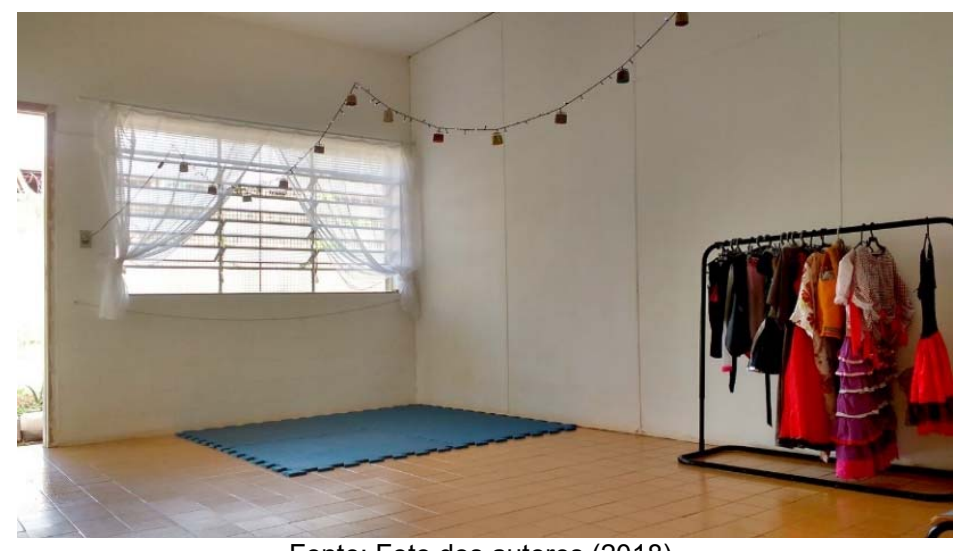

Fonte: Foto dos autores (2018).

Figura 9. Ateliê do CEEIAPC em galpão anexo.

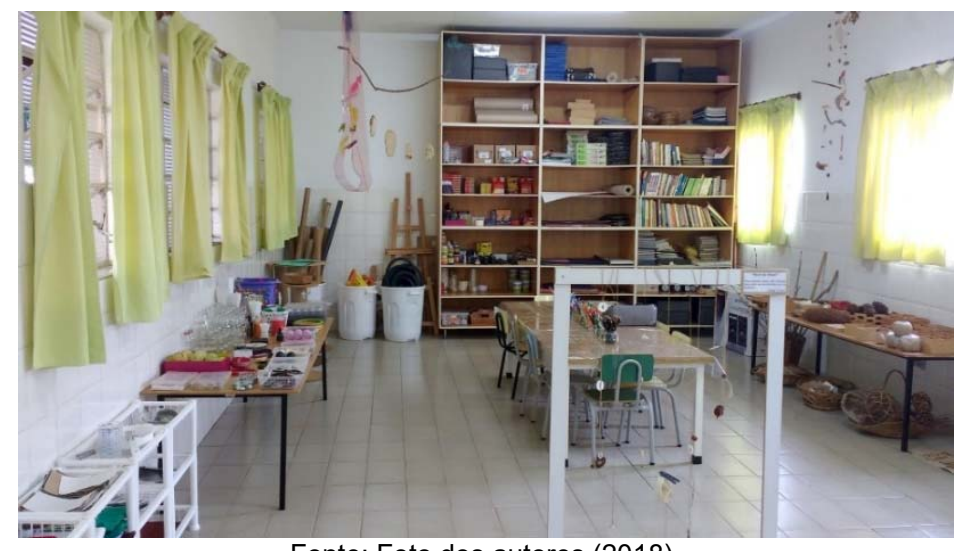

Fonte: Foto dos autores (2018). 
Figura 10. Elementos dispostos como "bancas de mercado" para uso das crianças no atelier. A oferta e disposição dos objetos de modo atraente é parte da orientação da abordagem.

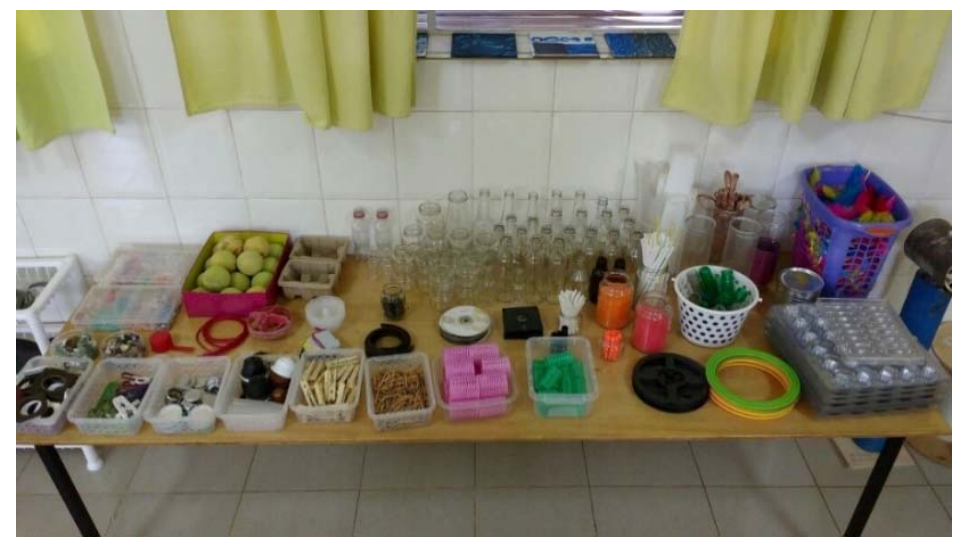

Fonte: Foto dos autores (2018).

\section{DISCUSSÃO DOS RESULTADOS E CONSIDERAÇÕES FINAIS}

Este artigo teve o objetivo de ressaltar a importância do espaço arquitetônico dentro de um ambiente de aprendizagem. Elegemos a abordagem de Reggio Emilia como objeto de estudo, pela relação estabelecida por essa filosofia pedagógica entre o processo de aprendizagem e o espaço do edifício e da cidade, escolhendo como estudo de caso uma escola infantil em Jundiaí, São Paulo.

É importante destacar que a transposição de ideias para o contexto de Jundiaí provocou um interessante processo de adaptação, que considera as características locais, trabalha com recursos e demandas existentes e desencadeia uma experiência nova. É preciso compreender o caráter experimental e meritório dessa experiência única, que mantém um contínuo processo de aperfeiçoamento sem visar reproduzir as escolas italianas, mas buscando construir, cotidianamente, uma escola no interior paulista. Na escola estudada, a relação com a população está amplamente baseada no papel social da creche e no reconhecimento da FAACG pela comunidade, devido à qualidade do trabalho social e educacional realizado nos vários níveis da educação desde a educação infantil.

Nossa pesquisa concentrou-se no âmbito do espaço da escola, buscando nos elementos arquitetônicos e de ocupação aspectos que refletissem uma preocupação pedagógica efetiva da diretoria e coordenação pedagógica para com os espaços.

Sobre o arcabouço espacial da escola analisada, cabe ressaltar que a escola foi implantada em um prédio existente que tem como característica um corredor longitudinal e grande área livre externa. Apesar de bem construído, o edifício com corredor ladeado por salas não corresponde ao arranjo de espaços previsto no programa básico de uma escola de Reggio Emilia. Há ausência de espaços importantes como a piazza e o hall. As salas, apesar de amplas e bem iluminadas, não possuem o espaço do mini-ateliê. Contudo, o corredor do edifício, a grande área livre externa e o galpão anexo, transformado num grande ateliê, foram reinterpretados pelos ocupantes da escola, o que demonstra uma disposição conciliatória entre meios e recursos, frente à impossibilidade de alteração drástica do edifício existente. Assim, até o presente momento, os aspectos mais importantes da abordagem de Reggio Emilia encontrados na creche em Jundiaí concentram-se no âmbito da ocupação e adequação interna dos espaços existentes pelos usuários.

Foi possível notar, na ocupação dos espaços da escola, as seguintes providências que alinham o uso do espaço ao pensamento adotado: ocorrência dos conceitos de "lugar de lugares"; "paredes que falam"; a presença do ateliê (enquanto um edifício anexo); e a importância da cozinha e do refeitório. O grande esforço coletivo em viabilizar e trazer os elementos essenciais da abordagem de Reggio Emilia é notadamente maior nos procedimentos pedagógicos e no estabelecimento das relações estabelecidas entre os atores envolvidos (crianças, comunidade e escola), se comparada aos aspectos edilícios.

Por fim, vale ressaltar que essa pesquisa aqui resumidamente apresentada foi desenvolvida buscando uma aproximação entre o campo da arquitetura e urbanismo e o campo da educação, de modo a contribuir com um olhar mais amplo para com a construção do espaço escolar, a partir de relações possíveis entre áreas diferentes do conhecimento. 


\section{REFERÊNCIAS}

BRUNER, J. Some specifications for a space to house a Reggio Preschool. In: CEPPI, G.; ZINI, M. Children, spaces, relations - Metaproject for an environment for young children. Cavriago: Grafiche Maffei, 2003.

CEPPI, G, ZINI, M. (org.). Children, spaces, relations - Metaproject for an environment for young children. Cavriago: Grafiche Maffei, 2003.

EDWARDS, C.; GANDINI, L.; FORMAN, G. As cem linguagens da criança: a abordagem de Reggio Emilia na Educação da Primeira Infância. Porto Alegre: Editora Artes Médicas Sul Ltda., 1999.

REGGIO CHILDREN. Everything has a shadow, except ants. Reggio Emilia, Italia: Loris Malaguzzi International Centre's BookFoodShop, 1999.

REGGIO CHILDREN. Mosaic of marks, words, materials. Reggio Emilia, Italia: Loris Malaguzzi International Centre's BookFoodShop, 2014.

RETRILLO, A. The project dream. In: CEPPI, G.; ZINI, M. Children, spaces, relations - Metaproject for an environment for young children. Cavriago: Grafiche Maffei, 2003.

RINALDI, C. Staff development in Reggio Emilia. In: KATZ, L.G.; CESARONE, B. Reflections on the Reggio Emilia Approach. Pennsykvania: ERIC/EECE, 1994.

SILVA, A. T. G. A. M. A construção da parceria família-creche: expectativas, pensamentos e fazeres no cuidado e educação da criança. Tese (Doutorado em Educação). Faculdade de Educação da Universidade de São Paulo, São Paulo, 2011

VECCHI, V. What kind of space for living well in school? In: CEPPI, G.; ZINI, M. Children, spaces, relations - Metaproject for an environment for young children. Cavriago: Grafiche Maffei, 2003.

NOTA DO EDITOR (*) O conteúdo do artigo e as imagens nele publicadas são de responsabilidade do(s) autor(es). 